\title{
Organizational Culture of HEIs: What matters the most?
}

\author{
DR. ANJUM IHSAN \\ Assistant Professor, Islamia College, Peshawar \\ anjumihsan@icp.edu.pk \\ ABID AHMAD \\ Lecturer, Dpertment of Management Sciences \\ CECOS University, Peshawar \\ abidcu@yahoo.com \\ DR. FAYYAZ ALI SHAH \\ Assistant Professor, Islamia College, Peshawar \\ Akhoon47@yahoo.com \\ HAMID ULLAH \\ Assistant Professor, Islamia College Pesahwar
}

\begin{abstract}
Culture and climate of an organization is valued to gain competitive advantage in today's modern organizations. This study aimed to analyze the relative importance of Artifacts, Espoused Beliefs \& Values and Basic Underlying Assumptions-the constituents of organization culture in relation to organization performance in Higher Education Institutes (HEIs) of district Peshawar. Cross-sectional data was collected from 250 employees of public and private sector universities working in drade-17 or above as teaching faculty or administrative staff using multi-stage cluster sampling technique. Findings indicated strong impact of constituents of organization cultural on organization performance and that the artifacts component has greater impact on organization performance than the other two components. Espoused beliefs and values have smaller impact than artifacts but greater impact than basic underlying assumptions and basic underlying assumptions have smallest impact. Thus leadership and management of HEIs should pay more and more attention to their tangible artifacts and making then more and more visible and ensuring their proper usage as this will lead to improvement in organization performance.
\end{abstract}

Keywords: Organization Culture, Artifacts, Espoused Beliefs and Values, Basic Underlying Assumptions, Organization Performance, HEIs Culture.

\section{Introduction}

Culture and climate of an organization is valued to gain competitive advantage in today's modern organizations. Culture is a complex issue that "comprises of shared values, beliefs, attitudes, artifacts, behavioral norms and assumptions" of members 
of an organization (Ogbonna \& Harris, 2002). It is shared thinking of minds which differentiate group associates from another similar group (Hofstede, 1980). Culture comprehend a group's principles, gained knowledge, explanations, theories, communication methods, beliefs and behavior in the same region and at the same instance of time (Kotler \& Heskett, 1992). In Higher Education Institutes (HEIs) culture is now linked with progress and success (Osman et al., 2010). Recent global progression of universities has led to the varying nature of HEIs. Each facet of all types of organizations is affected by the shifting political, societal and financial aspects, which made it imperative to research the culture of HEIs (Osman et al., 2010).

This study aimed to analyze the relative importance of Artifacts, Espoused Beliefs $\&$ Values and Basic Underlying Assumptions - the constituents of organization culture in relation to organization performance. The study investigated the constituents of organization culture in HEIs of district Peshawar and their relative contribution towards performance of HEIs. Three levels of cultural analysis Artifacts, Espoused Beliefs \& Values EBV and Basic Underlying Assumptions BUA described by Schein (2004) model of organization culture were used as unit of analysis. The study identified the constituent components of organization culture that affect performance more than other components and provided recommendations to managers and leaders of HEIs in Peshawar, Pakistan.

\section{Literature Review and Hypothesis Development 2.1 Organization Culture and its Constituents}

Numerous factors are ascribed as key elements for organization success and culture is among those listed at the top. Through decades of research, scholars (Schein 1990, 2004, Denison \& Mishra, 1995, Yilmaz \& Ergun, 2008) have established numerous links between various facets of organization culture and performance. Organizations today are aware of the fact that culture can be vital factor for acquisition of competitive edge (Schein, 2004). According to Hofstede (1980) culture is comprised of "a group's communal beliefs and values, attitudes, behavioral norms, assumptions and artifacts". Schein (1990) has described culture as "a set of different norms, behaviors and values leading to organization success". Pettigew (1979) put forth the culture of an organization as significant for the effectiveness of an organization, and leaders must develop the values and norms of an organization as well as of its members. According to Schein (1990) and Owens (1987) the organization's culture is an integration of collective beliefs and values that result in behavioral norms that help organizations to solve their problems. Culture signifies the organization inner environment and it constitute the assumption and beliefs of members of the organization (the managers and employees) (Yilmaz \& Ergun, 2008). It also enables effective and efficient achievement of organization goals (Yilmaz \& Ergun, 2008). Many researchers have discussed organization culture in different manners but the central idea is identical. According to Bagraim (2001), organization culture is characterized by great deal of conceptual difficulties in literature and do not has a single definition that is widely accepted.

\subsection{Schein Organization Culture Model}


Schein (2004) has formally defined culture as "pattern of common basic assumptions learnt by group members as the group solve its problems of exterior adaptation and internal integration, which have worked good enough to be taken valid and, therefore, to be taught to new group members as the right way to think, perceive and feel relative to those problems". Schein (2004) model of organization 


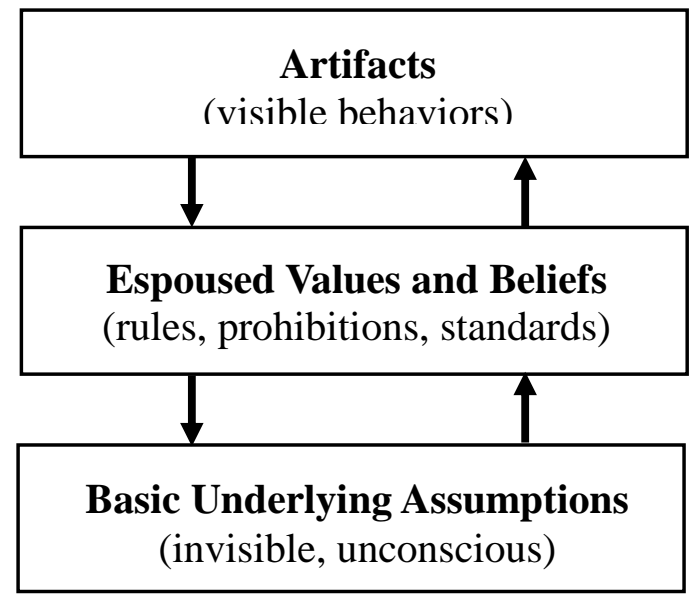

Figure 1: Levels of analysis of organization culture

(Source: Schein, 2004)

culture has proposed three levels of organizational culture, ranging from intensely embedded, unconscious assumptions to concrete appearances and manifestations that can be easily observed. Artifacts include everything that can be seen, heard, and felt when someone encounter an unfamiliar and unacquainted culture. Espoused beliefs and values are ethical and moral rubrics that are explicitly articulated and remain conscious, since the normative and/or ethical function to guide the group members is served by them. Deal \& Kennedy (1999) argue that adopted values are expressed and openly announced ideologies and standards that a group is striving to achieve. Solutions to problems are taken for granted when they repeatedly prove to be useful and these forms the basic underlying assumptions.

\subsection{Organization Culture in Higher Education Institutes (HEIs)}

Culture of an Organization is a vibrant component of effective \& efficient administrative practices in higher education institutes (HEIs). In HEIs culture is now linked with progress and success (Osman et al., 2010). Earlier culture was used by researchers to demonstrate the distinctiveness of culture among different kinds of HEIs (Kezar \& Eckel, 2002). However, recent global progression of universities has led to varying sort of HEIs. Each facet of organizations is affected by the shifting political, societal and financial aspects, which made it imperative to research the culture of HEIs (Osman et al., 2010). Universities globally have experienced growing pressures through the preceding two decades to adapt to swiftly varying forces originating from external environment (Bartell, 2003). Culture of university is a distinctive form of organization culture where beliefs, values and basic underlying assumptions are to greater extent common in all universities (Salonda, 2008). Kuh \& Whitt (1988) defined university culture as, "commonly shared patterns of standards, beliefs, values, practices, conventions and norms that are used to guide groups and individuals' behavior". 


\subsection{Organization Performance and Culture}

Performance and effectiveness of organization is a widely investigated matter since the introduction of theory of organization (Jean-Francois, 2004). Creation of value is the spirit of organization performance (Carton, 2004). As long as the value created by using the devoted assets is greater than or at least equal to the expected value, the assets will be made available to the organization (Carton, 2004). Corporates are equated in standings of stock prices, revenues, incomes, debt ratios, efficiency and market proportion (March \& Sutton, 1997). Organizations generally use financial indicators for performance measurement. Such indicators may be deprived of forecasting and predicting function, might not emphasize on the processes but only the operative outcomes, and never explain the cause and effect of operative outcomes (Jyoti et al., 2006). The performance measurement of nonprofit organizations is studied extensively but the findings are generally inconclusive (Forbes, 1998). For assessment of performance exam scores, rankings and grading by magazines, research output and standing of faculties are used by universities (March \& Sutton, 1997). Cunha \& Miller (2012) reported that a single measure might not aggregate such diverse and dynamic dimensions accurately, therefore, a group of indicators is required for quantitative measures of institutional performance. Organization performance is associated with organization culture by plethora of research studies. Scholars Lee and Yu (2004) has positively linked various facets of organization culture with performance. Haslinda \& Tee (2018) found no association between culture and performance but argued that this do not signify culture as a less important factor. Anra \& Yamin (2017) also argued that organization culture directly affects the performance of university lecturers and thus the performance of HEIs.

\subsection{The Balance Scorecard for Non-Profit Organization}

Kaplan (2001) proposed Balance Scorecard (BSC) for non-profit organizations, which was later revised by Jyoti et al., (2006) and Iselin et al., (2009). Theme of the proposed Balance Scorecard is that accomplishment for not-for-profit organization cannot solely be measured using financial measures. Performance assessment methods for such organization should also consider other factors such as internal process, learning and growth and customer perspective. The early emphasis of the BSC was in private for-profit firms. But it was effectively applied in not-for-profit sector, as a result of a research study that applied the BSC to numerous not-for-profit organizations. The financial perspective of BSC defines how firms desires to be perceived by its stockholders. Objectives of an organization from financial perspective will include cost effectiveness, maximizing shareholders' wealth, influence sales of the company and/or product, timely acquisition of funds, minimizing cost of capital, arrange funds from external sources, improve returns and continuous flow of funds. Customer Perspective of BSC's assess the firm performance through targeted buyers and market segments. This is done by means of outcome-oriented measures such as gaining new customer and their retention, market proportion, and profitability. Internal process perspective is based on measurement of operating performance like cycle times, quality and cost of critical processes and procedures that are significant for value 
creation. Learning and growth ascend from sources like systems and people. Workforce retention, motivation and competences, and the proficiency of information system are typical measures of this perspective.

\subsection{Conceptual Model}

Conceptual model for this study is based on the progression in knowledge of organization culture and its corresponding impact on organizational performance. The conceptual model presents the association among the study variables - the three levels (Artifacts, Espoused Beliefs \& Values and Basic Underlying Assumptions) of cultural analysis and four perspectives of balance scorecard to assess organization performance.

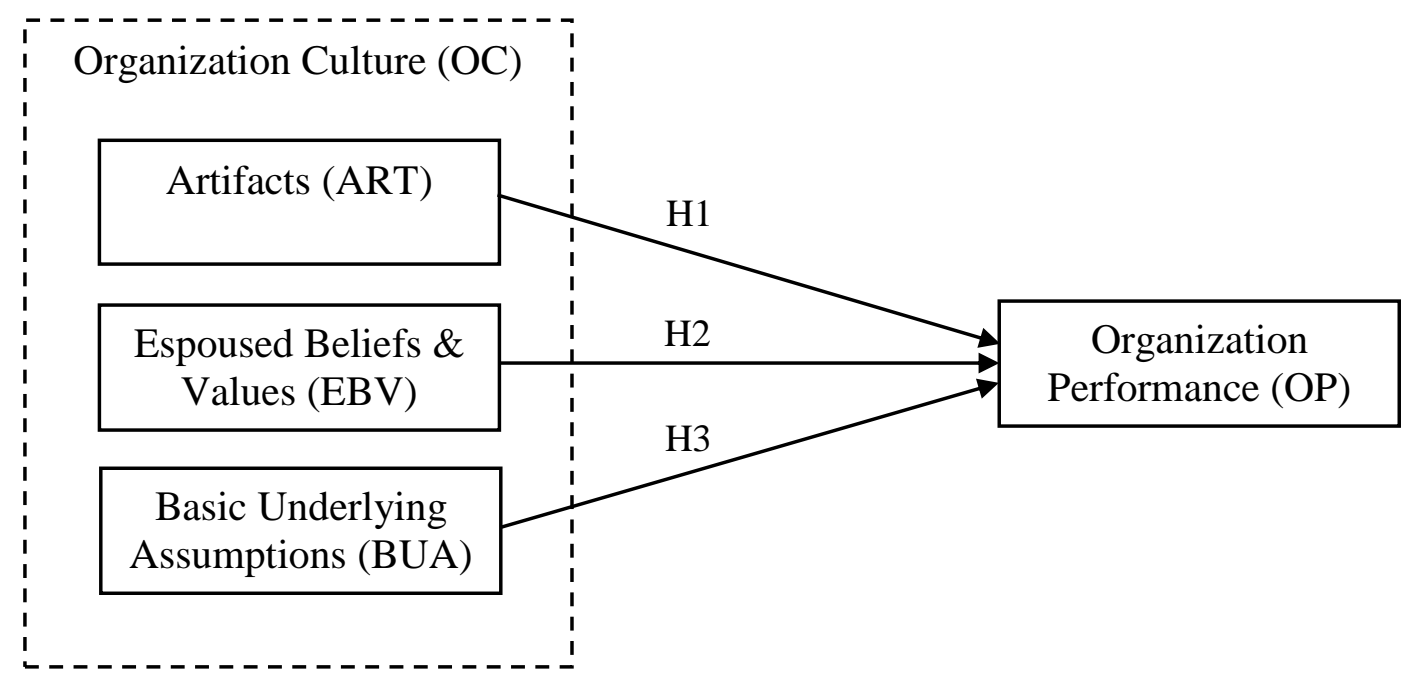

Figure 2: Conceptual Model for this study.

\subsection{Hypotheses}

Based on the conceptual model following hypothesis are proposed.

H1:Artifacts (ART) the constituent component of organization culture is positively related to Organizational Performance (OP).

H2: Espoused Beliefs \& Values (EVB) the constituent component of organization culture has a positive impact on Organization Performance (OP).

H3:The constituent of organization culture Basic Underlying Assumptions $(B U A)$ is positively associated with Organizational performance (OP).

\section{Research Methodology}

\subsection{Research Design}

To explore the nature of association among the variables a causal-hypothetical model is followed by this study. Findings are based on empirical testing of analyzing the association of organization performance and organization culture and nature of the research is quantitative, and statistical techniques are used to approve the hypothesis. The rationale for selecting the quantitative correlational and regression design method is that correlation helps in measuring the strength of 
relationship among variables and regression helps to reveal the dependence between the variables.

\subsection{Sampling Procedure}

Target population for the present study comprised of Grade-17 and/or above teaching faculty and administrative employees of universities of Peshawar having at least 3 years of job experience in the university. Multi-stage cluster sampling technique was used to first select six universities (three from public sector and three from private sector) from the total 15 universities at first stage of the sampling. At the second stage a sample of 290 employees was selected through simple random sampling.

\subsection{Measures}

Measures used were well established, simple to comprehend and straight forward in language. An integrated questionnaire survey that combined the demographic questions and instruments of the variables was developed for this research. All items were captured using a five point Likert scale consisting of responses ranging strongly disagree $=1$ to strongly agree $=5$, except for demographics. The validity and reliability of survey questionnaire for this study, was checked by using Cronbach's alphas on the levels of organizational culture and performance variables. Overall Cronbach's alpha of the scale was computed to be 0.89. Survey questionnaires were circulated among the selected universities employees and collected back. The questionnaires were then checked for completeness. Blank or extensively incomplete questionnaires were barred from processing. From the remaining questionnaires missing values were coded with "99" during processing. Out of total 290 questionnaires 278 (95.8\%) were returned. Out of the 268 returned questionnaires 18 were barred and $250(89.6 \%)$ were processed.

\section{Data Analysis and Results}

\subsection{Reliability Statistics}

Internal consistency of variables with each other was measured by computing Cronbach alpha. According to George \& Mallery (2003) reliability coefficient of 0.90 or greater is considered to be excellent one, coefficient value of 0.80 or greater is considered to be good, the value of 0.70 or higher is acceptable, the value around 0.60 is questionable, coefficient value of 0.50 is considered to be poor and value lesser than 0.50 is usually unacceptable. For this study Cronbach alpha is computed to be 0.89 which is excellent and suggest that items are highly internally consistent.

Table 1: Mean, Standard Deviation and Correlations

\begin{tabular}{|c|c|c|c|c|c|c|c|c|c|}
\hline Variables & Mean & SD & 1 & 2 & 3 & 4 & 5 & 6 & 7 \\
\hline 1. Age & 33.0 & 7.45 & & & & & & & \\
\hline 2. Gender ${ }^{\mathrm{a}}$ & 1.27 & .391 & -.020 & & & & & & \\
\hline Education $^{\mathrm{b}}$ & 3.39 & .992 & $.564 *$ & -.009 & & & & & \\
\hline $\begin{array}{ll}\text { 4. Experienc } \\
\mathrm{e}\end{array}$ & 7.05 & 5.18 & .406 & .086 & .061 & & & & \\
\hline
\end{tabular}




$\begin{array}{lllllllllll}\text { 5. } & \text { ART } & 4.347 & .814 & .120 & .183 & .261 & .206 & & \\ \text { 6. } & \text { EBV } & 4.142 & .725 & .017 & .152 & .093 & .374 & .519^{* *} & \\ \text { 7. } & \text { BUA } & 3.925 & .643 & .119 & .431 & .351 & .247 & .345^{* *} & .517^{* *}\end{array}$

Table 2: Results of least square regression analysis

\begin{tabular}{ll}
\hline Variables & Organization Performance \\
\hline Constant & $0.615^{* *}$ \\
Artifacts & $0.428^{* *}$ \\
Espoused Beliefs \& Values & $0.423^{* *}$ \\
Basic Underlying Assumptions & $0.259^{* *}$ \\
$\boldsymbol{R}^{2}$ & $0.643^{* *}$ \\
$\boldsymbol{F}$ & $106.96^{* *}$ \\
\hline
\end{tabular}

Note: $\mathrm{N}=250,{ }^{*} \mathrm{p}<0.05$ (2-tailed), $* * \mathrm{p}<0.01$ (2-tailed)

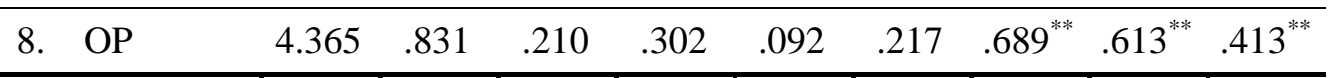

Note: $\mathrm{N}=250,{ }^{*} \mathrm{p}<0.05$ (2-tailed), $* * \mathrm{p}<0.01$ (2-tailed)

${ }^{\text {a }}$ Gender: $1=$ male, $2=$ female

${ }^{\mathrm{b}}$ Education: 1= High school, 2=College, 3=Bachelors, 4=Masters, 5=MS/M Phil, 6=PhD

\subsection{Descriptive Statistics and Inter-correlations}

Descriptive statistics and correlations for all the variables of the study are summarized in Table 1. It can be seen that organization performance is associated positively with artifacts $(r=.689, p<.01)$, espoused beliefs and values $(r=.613$, $p<.05)$ and basic underlying assumptions $(r=.413, p<.01)$. However, the strength of relationship of performance with basic underlying assumptions is relatively less than with artifacts and espoused beliefs and values.

\subsection{Hypothesis testing}

Hypothesis $\mathrm{H} 1$ predicted that the artifact constituent of organization culture is positively associated with organization performance. Correlation analysis (Table 1) and least square regression analysis (Table 2 ) conformed this hypothesis $(\beta=.428$, $\mathrm{p}<.01)$. Hypothesis $\mathrm{H} 2$ predicted that espoused beliefs and values is positively related to organization performance. Correlation analysis (Table 1) and least square regression analysis (Table 2$)$ conformed this hypothesis $(\beta=.423, \mathrm{p}<.01)$ as well. However, the impact of espoused beliefs and values on organization performance is relatively lower than the impact of artifacts on performance. 
Hypothesis $\mathrm{H} 3$ predicted that basic underlying assumptions is positively associated with organization performance. Correlation analysis (Table 1) and least square regression analysis (Table 2$)$ also conformed this hypothesis $(\beta=.259, \mathrm{p}<.01)$. However, the impact of basic underlying assumptions on organization performance is lower than the impact of both artifacts and espoused beliefs and values on organization performance. Based on the results the regression model can be defined as,

$$
O P=.615+0.428(A R T)+0.423(E B V)+0.259(B U A)
$$

The model defines that organization performance is positively associated with all the three constituent of organization culture. The slopes of the model indicate that for a unit change in ART, the value of OP will change by 0.428 units while for the unit change in EBV, the value of OP will change by 0.423 and for the unit change in BUA, there is a change in OP by 0.259 units.

\section{Discussion}

The current study reported strong impact of constituents of organization cultural on organization performance in HEIs of district Peshawar. The findings were consistent with the study of Lee and Yu (2004) that found corporate culture to impact organizational performance. The data analysis indicated a positive as well as significant relationship exists between the independent (basic underlying assumptions, espoused beliefs and values and artifacts) and dependent (organization performance) variables. The study results also confirmed the results of past research, indicating a strong positive relationship exists between organizational performance and elements of organizational culture. However, artifacts component has greater impact on organization performance than the other two components. Espoused beliefs and values have smaller impact than artifacts but greater impact than basic underlying assumptions and basic underlying assumptions have smallest impact. Being highly invisible, basic underlying assumptions have smallest impact on organization performance. This means that no matter how good the basic underlying assumptions are, unless they are not represented in publically articulated values and visible artifacts increased performance may not be guaranteed.

\subsection{Limitations and Future research}

This research is not without limitations, which future research may address. First the data was gathered from a single type of organizations (i.e., HEIs), which limits the generalization to other sort of organizations. Future research may extend the study to other settings. Second, future research might use longitudinal and experimental designs as this research used cross-sectional design. Third, a considerable future research area involves expanding the population of the study to provincial and/or national level. This may help in confirming and generalizing the findings of this study. Fourth, area of future research involves to investigate the influence of individual artifacts or set of artifacts on organization performance and to isolate the artifacts with more impact and significance than the ones with less impact. Fifth, future research might find out appropriate set of values and proposed a value system for HEIs that better serve to enhance their performance. 


\subsection{Implications \& Conclusion}

Among the constituent components of organization culture, the artifacts have greatest impact on organization performance in HEIs of district Peshawar. Thus leadership and management of HEIs should pay more and more attention to their equipment and products, architecture of physical environment, language, arty creations, emotional displays, comportments of address, stories and myths, published lists of values, rituals and rites and other artifacts. Making the artifacts more and more visible and ensuring their proper usage will lead to improvement in organization performance. Although smaller than the artifacts but espoused beliefs and values do have an impact on organization performance. HEIs should also strive to develop and disseminate a value system. Explicitly articulated values and implementation of moral and ethical rules will also lead to improved performance. As it is evident from the results of the present study that organization culture positively affects organization performance, the regulatory bodies like HERA, HEC and Higher Education Department should establish a system to evaluate organization culture of universities.

\section{References}

Anra, Y., \& Yamin, M. (2017). Relationships between lecturer performance, organizational culture, leadership, and achievement motivation. Фopcaŭm, 11(2 (eng)).

Bagraim, J. J. (2001). Organizational Psychology and Workplace Control: The Instrumentality of Corporate Culture. South Africa Journal of Industrial Psychology, 3(1), pp. 43-49.

Bartell, M. (2003). Internationalization of Universities: A University CultureBased Framework. Higher Education, 45 (1), pp. 43-70.

Carton, R. B. (2004). Measuring Organizational Performance: An Exploratory Study (Doctoral Dissertation). University of Georgia, Athens, Georgia.

Cunha, J. M., \& Miller T. (2012). Measuring Value-Added in Higher Education. HCM Strategists LLC. Washington, DC, p. 32

Deal, T. E. \& Kennedy, A. A. (1999). The new corporate cultures: Revitalizing the workplace after downsizing, mergers, and reengineering. Perseus Books (Reading, Mass.), ISBN 0738200697.

Denison, D. R., \& Mishra, A. K. (1995). Toward a theory of organizational culture and effectiveness. Organization Science, 6, pp. 204-223.

Forbes, D. P. (1998). Measuring the Unmeasurable: Empirical Studies of Nonprofit Organization Effectiveness from 1977 to 1997. Nonprofit and Voluntary Sector Quarterly, 27 (2), pp. 183-202.

George, D. \& Mallery, P. (2003). SPSS for Windows step by step: A simple guide and reference (4th ed.). Boston: Allyn \& Bacon.

Haslinda, A., \& Tee, C. K. (2018). Direct Effect of Technology, Human Resource Flexibility, Leadership and Culture on Firm Performance. IJASSH.

Hofstede, G. (1980). Culture's Consequences: International differences in work related values. Beverly Hill, CA: Sage. 
Iselin, E., Sands, J. \& Lokman, M. (2009). Multi-perspective Performance Reporting, Continuous Improvement and Organizational Performance. Accounting and Finance Association of Australia and New Zealand (AFAANZ) conference. Adelaide, Australia.

Jean-Francois, H. (2004). Performance measurement and organizational effectiveness: bridging the gap. Managerial Finance, 30(6), pp. 93 - 123

Jyoti, Banwet, D. K., \& Deshmukh, S. G. (2006). Balanced Score Card for Performance Evaluation of R \& D Organization: A Conceptual Model. Journal of scientific \& Industrial Research, 65, pp. 879-886.

Kaplan, R. S. (2001). Strategic Performance Measurement and Management in Nonprofit Organizations. Nonprofit Management and Leadership, 11(3), pp. 353370.

Kezar, A., \& Eckel, P. D. (2002). The effect of institutional culture on change strategies in higher education. The Journal of Higher Education, 73(4), pp. 435460.

Kotler, P., \& Heskett, L. (1992). Corporate Culture and Performance. New York: Macmillan.

Kuh, G. D., \& Whitt, E. J. (1988). The invisible tapestry: Cultures in American colleges and universities. ASHE-ERIC Higher Education Report No. 1. Association for the Study of Higher Education, Washington, D.C.

Lee SKJ, Yu K (2004) Corporate culture and organizational performance. Journal of Managerial Psychology, 19(4):340-359.

March, G. J. (1991). Exploration and Exploitation in Organizational Learning. Organization Science, 2(1), pp. 71-87.

Ogbonna, E., \& Lloyd, C. H. (2002). Managing organizational culture: insights from the hospitality industry. Human Resource Management Journal, 12, (1), pp 33-53.

Osman, F. B., Munevver, Y. M., Dogan, \& Nermin, K. (2010). The Organizational Culture at the University. International Journal of Educational Researchers, 2(1), pp. 1-13.

Owens, R., (1987). Organizational Behavior in Education. New Jersey: PrenticeHall.

Pettigrew, A. (1979). On Studying organizational culture. Administrative Science Quarterly, 24(4), pp. 570-581.

Salonda, L. L. (2008). Exploration of a university culture: A Papaua New Guinea case study. (Unpublished Doctoral Dissertation). Victory University of Technology.

Schein, E. H. (1990). Organizational culture. American Psychologist, 45(2), pp. 109-119.

Schein, E. H. (2004). Organizational culture and leadership (3rd ed.). The JosseyBass business \& management series. John Wiley \& Sons.

Yilmaz, C., \& Ergun, E. (2008). Organizational culture and firm effectiveness: An examination of relative effects of culture traits and the balanced culture hypothesis in an emerging economy. Journal of World Business, 43, pp. 290-306. 